http://jmscr.igmpublication.org/home/ ISSN (e)-2347-176x ISSN (p) 2455-0450

crossref DOI: https://dx.doi.org/10.18535/jmscr/v7i12.23

Journal Of Medical Science And Clinical Research

\title{
Histopathological Spectrum of Endometrium in Perimenopausal and Postmenopausal Women in a Tertiary Care Center
}

\author{
Authors \\ Dr P.S.Mulay ${ }^{1}$, Dr Soundararajan Rama², Dr S.A. Deshpande ${ }^{3}$ \\ ${ }^{1,2}$ Assistant Professor, Dept. of Pathology, Dr SCGMC Nanded \\ ${ }^{3}$ Associate Professor, Dept. of Pathology, Dr SCGMC Nanded
}

\begin{abstract}
Introduction: The endometrium is uniquely endowed throughout the female reproductive lifespan with complex of periodic proliferation, differentiation, breakdown and regeneration. Virtually every woman will at some point in her lifetime experiences episodes of bleeding that are perceived as abnormal ${ }^{2}$. Sampling of endometrium should be considered in all women over the age of 40 years with abnormal bleeding in order to diagnose benign and malignant conditions that are very often found among postmenopausal women.

Aims And Objectives

1. To determine various histological patterns of endometrium in peri and postmenopausal women.

2. To analyse the causes of abnormal vaginal bleeding after histopathological examination in peri and postmenopausal women.

3. To correlate between clinical and histopathological findings of endometrium in peri and post menopausal women.
\end{abstract}

Materials and Methods: This 18 months study was done in Department of Pathology, Dr SCGMC Nanded from january2017-june2018 which included D\&C, Endometrial biopsies, curettage and resected specimens of uterus. Histopathological spectrum of endometrium in 340 Female patients in the perimenopausal group $(45 \pm 5$ years) and postmenopausal group (50 years and above) with symptoms of bleeding were studied.

Results: Maximum incidence was found in the age group of 41-50 years perimenopausal (64.7\%). Menorrhagia was most common bleeding pattern found in $67.65 \%$. Postmenopausal bleeding was common in atrophic endometrial profiles (47.5\%). Among the perimenopausal women, the most common pattern was Proliferative endometrium (58.64\%) and the commonest pathology was Simple endometrial hyperplasia (5.0\%). Among the postmenopausal women, the most common pattern was Atrophic endometrium (47.5\%) and the commonest pathology was Simple endometrial hyperplasia (5.0\%). Out of 5 malignant cases, 4 cases were found to be endometrial adenocarcinoma and 1 case was found to be endometrial stromal sarcoma.

Conclusion: Sampling of endometrium should be considered in all women over the age of 40 years with abnormal bleeding in order to diagnose benign and malignant conditions and also to decide the mode of treatment to be given.

Keywords: Abnormal uterine bleeding, Perimenopausal and postmenopausal bleeding.

\section{Introduction}

Endometrium is the mirror of hormonal status in a woman.
Olshausen gave the first histological description of the endometrium. ${ }^{1}$ 
The endometrium is uniquely endowed throughout the female reproductive lifespan with complex of periodic proliferation, differentiation, breakdown and regeneration. Virtually every woman will at some point in her lifetime experiences episodes of bleeding that are perceived as abnormal ${ }^{2}$. Menstrual abnormalities is the cause of discomfort, inconvenience and disruption of healthy social and physical lifestyles among millions of women worldwide. It can be caused by a wide variety of disorders, some of which represent normal physiological process, while others are a sign of serious underlying pathology Perimenopause is the phase, preceding the onset of menopause, generally occurring around 40 years of age during which the regular menstrual cycle of a woman changes from normal ovulatory cycles to a pattern of irregular cycles ${ }^{3,4}$. Menopausal transition includes a period of about 4-5 years before menopause, sometimes even several months, characterized by varying degrees of somatic and psychological changes that reflect the change in the ovarian cycle ${ }^{5}$.In some women, the most significant symptom is an irregular menstrual period, which must be carefully evaluated to determine whether it is the consequence of low oestrogen levels or an associated pathology 6 .

During the perimenopausal era the different types of bleeding irregularities supervene such as polymenorrhea, menorrhagia, metrorrhagia, menometrorrhagia,

Cryptomenorrhea,

hypomenorrhoea,

oligomenorrhoea,

dysmenorrhoea etc. ${ }^{7,8}$ These menstrual irregularities often arise when a women proceeds towards menopause and after menopause i.e. in women over 40 years of age. These occur as a consequence of different histopathological changes in the endometrium. Amongst them the important ones are endometrial carcinoma, endometrial hyperplasia, endometrial polyp, endometrial stromal tumour, endometritis (acute and chronic), effects of exogenous hormone (e.g. longstanding estrogen therapy, tamoxifen therapy),

adenomyosis,

leiomyoma, leiomyosarcoma etc. With usual waning of oestrogen secretion at perimenopausal period the endometrium may specially undergo dramatic changes. Histological study of the endometrium is the most common investigation employed by Gynaecologists throughout the world to evaluate abnormal uterine bleeding, and is particularly important in postmenopausal women to rule out malignancy and thereby plan for treatment modalities. Abnormal perimenopausal or postmenopausal bleeding is associated with endometrial carcinoma in approximately $10 \%$ of cases. $^{9,10}$

The purpose of this review is to focus on the hormonal and physiologic changes that are associated with perimenopausal and postmenopausal vaginal bleeding, to present the essential evaluation of causes for this flow, and to outline the evidence for effective medical and surgical treatments. Advances in the understanding of the normal physiology of perimenopause have led to medical therapies that may lead to fewer surgical procedures and hysterectomies and should be of interest to health care practitioners focusing on women's health. ${ }^{11}$

\section{Aims and Objectives}

1) To determine various histological patterns of endometrium in peri and postmenopausal women.

2) To analyse the causes of abnormal vaginal bleeding after histopathological examination in peri and postmenopausal women.

3) To correlate between clinical and histopathological findings of endometrium in peri and post menopausal women.

\section{Material and Methods}

The study "Histopathological spectrum of endometrium in perimenopausal and postmenopausal women in a Tertiary Care Centre" was conducted on 340 cases in the Department of Pathology, Dr. SCGMC, Nanded from January 2017 to June 2018. 


\section{Inclusion Criteria}

1. All patients in the perimenopausal group (45 \pm 5 years) and post menopausal group (50 years and above) presenting with abnormal uterine bleeding.

2. Married and unmarried.

3. Nulliparous and multiparous

\section{Exclusion Criteria}

1. Patients less than 40 years of age.

2. Patients presenting with abnormal uterine bleeding due to non endometrial causes like lesions of the myometrium and adnexa.

Female patients in the perimenopausal group (45 \pm 5 years) and postmenopausal group (50 years and above) with symptoms of bleeding admitted in the Inpatient wards of Department of Obstetrics and Gynaecology has been studied.

\section{Results}

In this study, spanning from January 2017 to june 2018, endometrial biopsies, D\& C samples, and hysterectomy specimens of patients presented with abnormal bleeding were studied. Out of 340 cases, maximum number of patients were in the age group of perimenopausal (41-50 years) age group $220(64.70 \%)$ and $120(35.30 \%)$ cases were in postmenopausal ( $>50$ years) age group.

Table No.1: Age Incidence of Perimenopausal Bleeding cases

\begin{tabular}{|l|c|c|}
\hline Age ( In Years) & $\begin{array}{c}\text { No Of Cases } \\
(\mathbf{n = 2 2 0})\end{array}$ & Percentage (\%) \\
\hline $40-45$ & 193 & 87.73 \\
\hline $46-49$ & 27 & 12.27 \\
\hline TOTAL & $\mathbf{2 2 0}$ & $\mathbf{1 0 0}$ \\
\hline
\end{tabular}

Table No.2: Age Incidence of Postmenopausal Bleeding cases

\begin{tabular}{|l|c|c|}
\hline Age ( In Years) & $\begin{array}{c}\text { No of Cases } \\
(\mathbf{n = 1 2 0})\end{array}$ & $\begin{array}{c}\text { Percentage } \\
(\mathbf{\%})\end{array}$ \\
\hline $50-55$ & 62 & 51.67 \\
\hline $56-60$ & 29 & 24.16 \\
\hline $61-65$ & 12 & 10 \\
\hline $66-70$ & 12 & 10 \\
\hline $71-75$ & 5 & 4.17 \\
\hline TOTAL & $\mathbf{1 2 0}$ & $\mathbf{1 0 0}$ \\
\hline
\end{tabular}

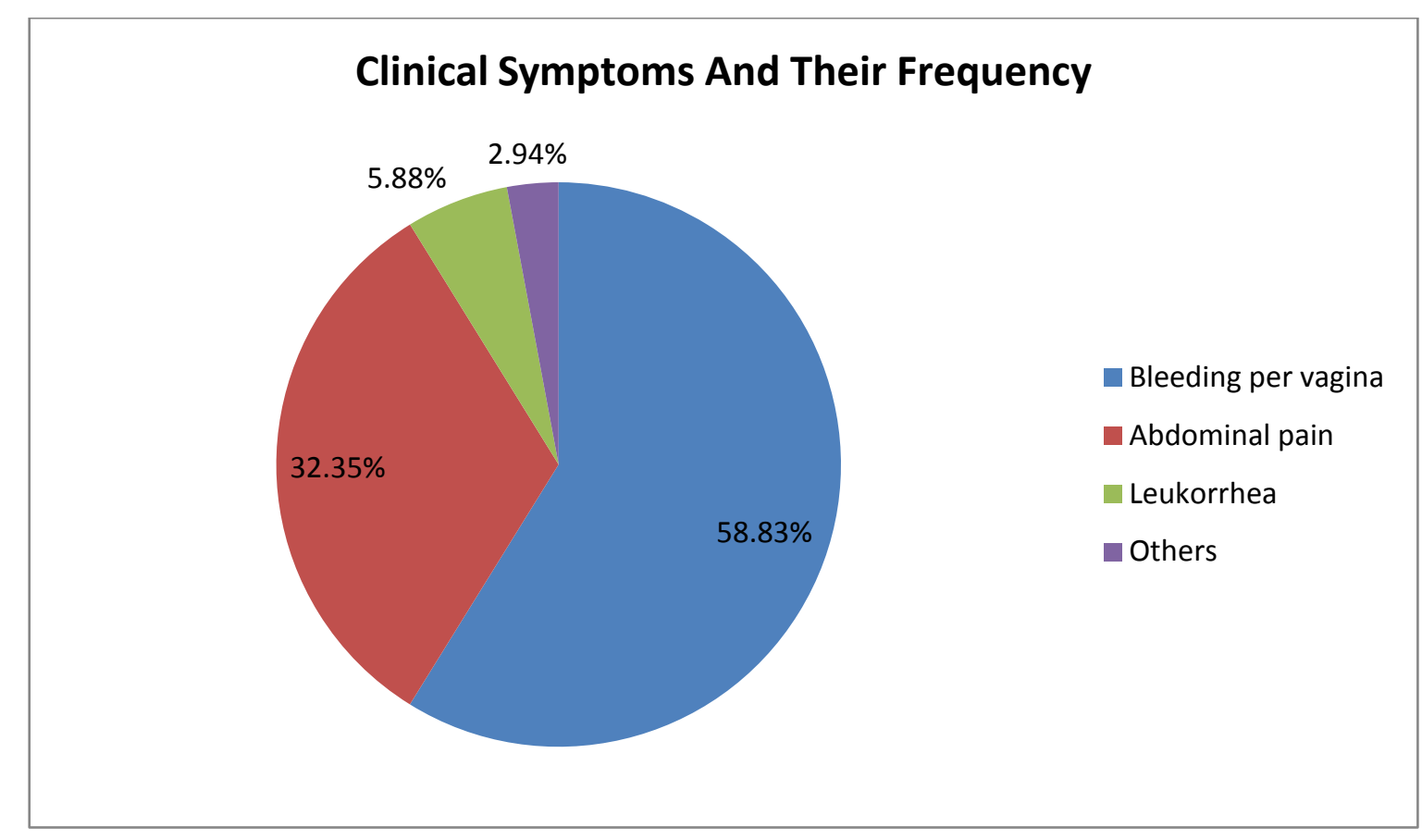



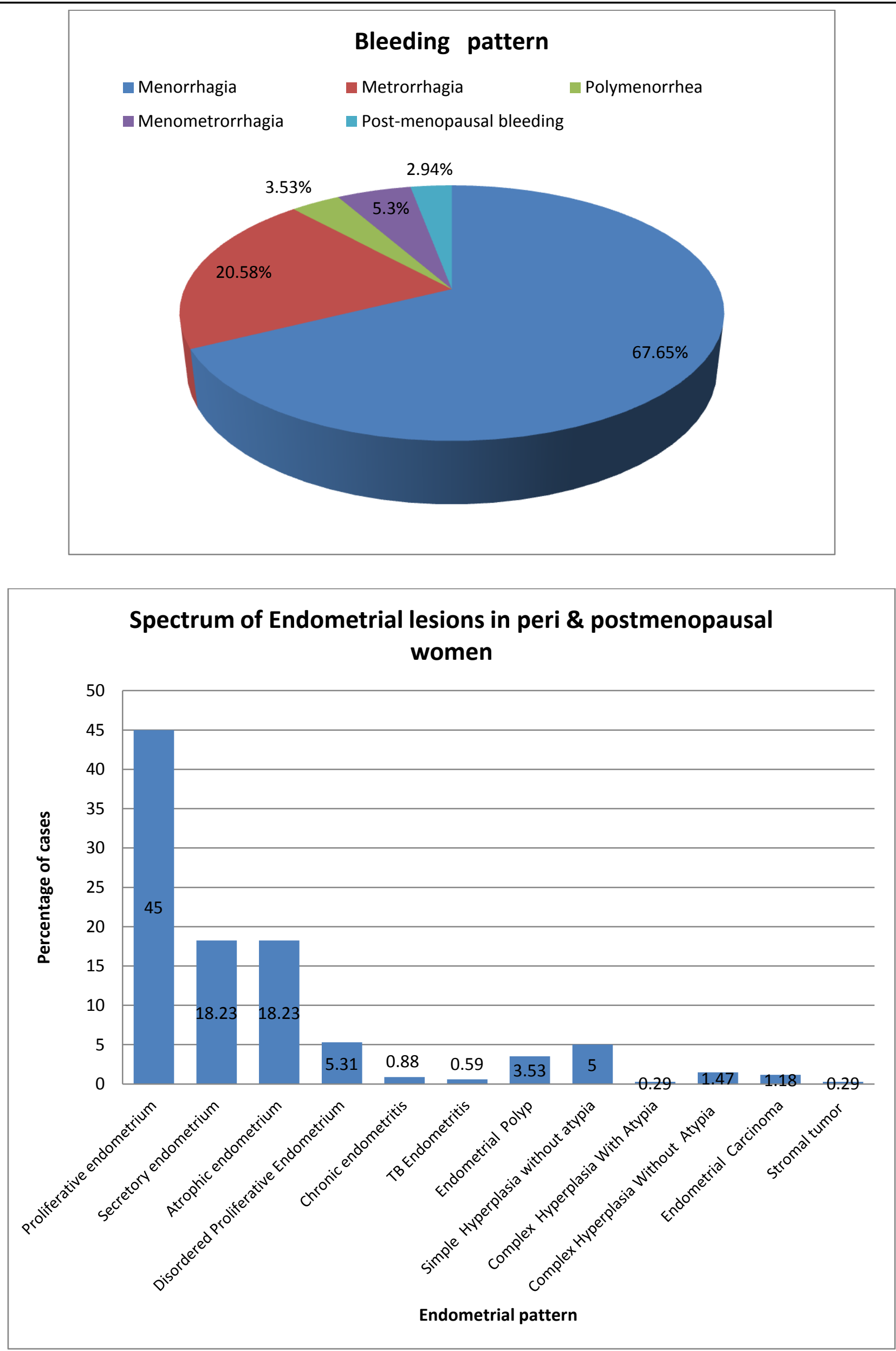


\section{JMSCR Vol||07||Issue $\| 12||$ Page 116-123||December}

Table No.3 : Spectrum of endometrial pattern in perimenopausal and postmenopausal women

\begin{tabular}{|l|c|c|c|c|}
\hline Endometrial Pattern & $\begin{array}{c}\text { No.Of Cases } \\
(\mathbf{n = 2 2 0})\end{array}$ & Percentage(\%) & $\begin{array}{c}\text { No.Of Cases } \\
(\mathbf{n = 1 2 0})\end{array}$ & Percentage(\%) \\
\hline Proliferative endometrium & 129 & 58.64 & 24 & 20.0 \\
\hline Secretory endometrium & 47 & 21.36 & 15 & 12.5 \\
\hline Atrophic endometrium & 5 & 2.28 & 57 & 47.5 \\
\hline Disordered Proliferative Endometrium & 8 & 3.64 & 10 & 8.34 \\
\hline Chronic endometritis & 3 & 1.36 & 0 & 0 \\
\hline TB Endometritis & 2 & 0.90 & 0 & 0 \\
\hline Endometrial Polyp & 9 & 4.10 & 3 & 2.5 \\
\hline Simple Endometrial Hyperplasia & 11 & 5.0 & 6 & 5.0 \\
\hline Complex Hyperplasia With Atypia & 1 & 0.45 & 0 & 0 \\
\hline Complex Hyperplasia Without Atypia & 4 & 1.82 & 1 & 0.83 \\
\hline Endometrial Carcinoma & 1 & 0.45 & 3 & 2.5 \\
\hline Stromal tumor & 0 & 0 & 1 & 0.83 \\
\hline TOTAL & $\mathbf{2 2 0}$ & $\mathbf{1 0 0}$ & $\mathbf{1 2 0}$ & $\mathbf{1 0 0}$ \\
\hline
\end{tabular}

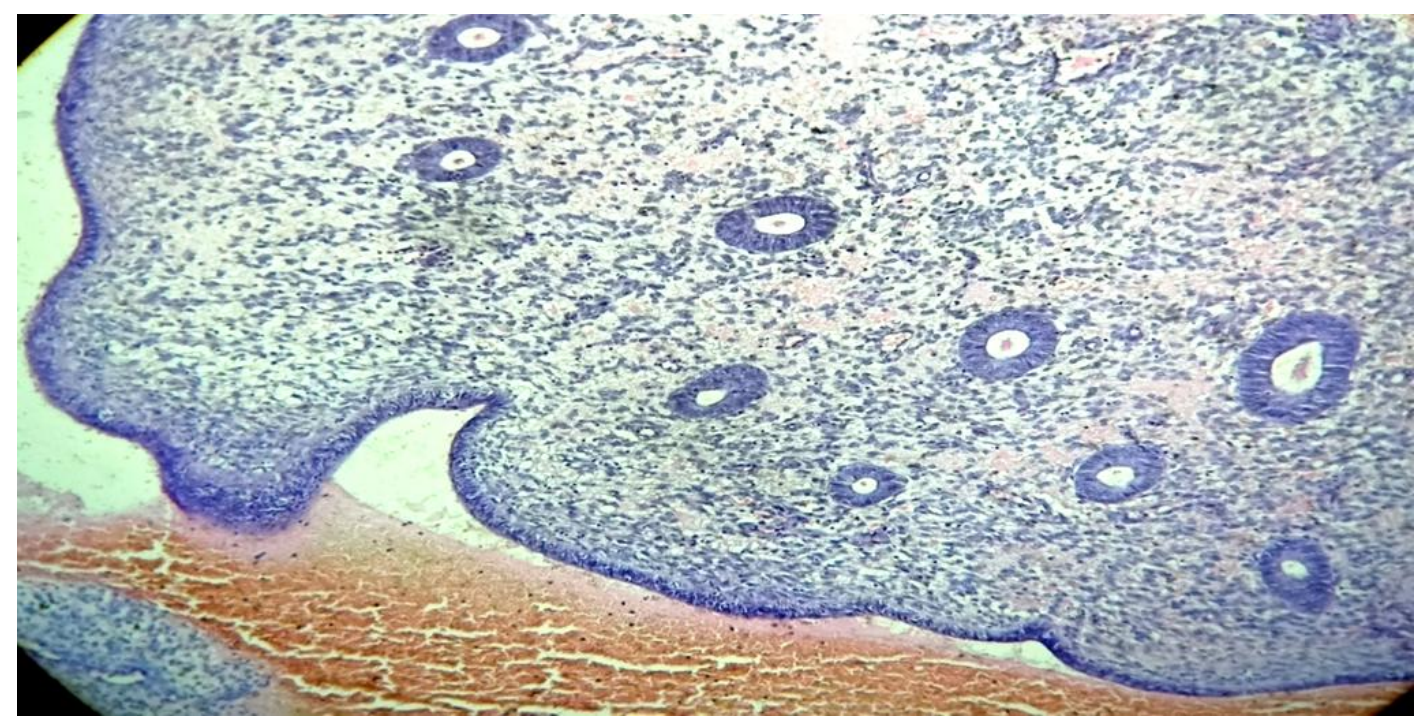

Photo no.1: Endometrial polyp showing lining epithelium and glands surrounded by compact stroma. $(\mathrm{H} \& \mathrm{E}, 10 \mathrm{X})$

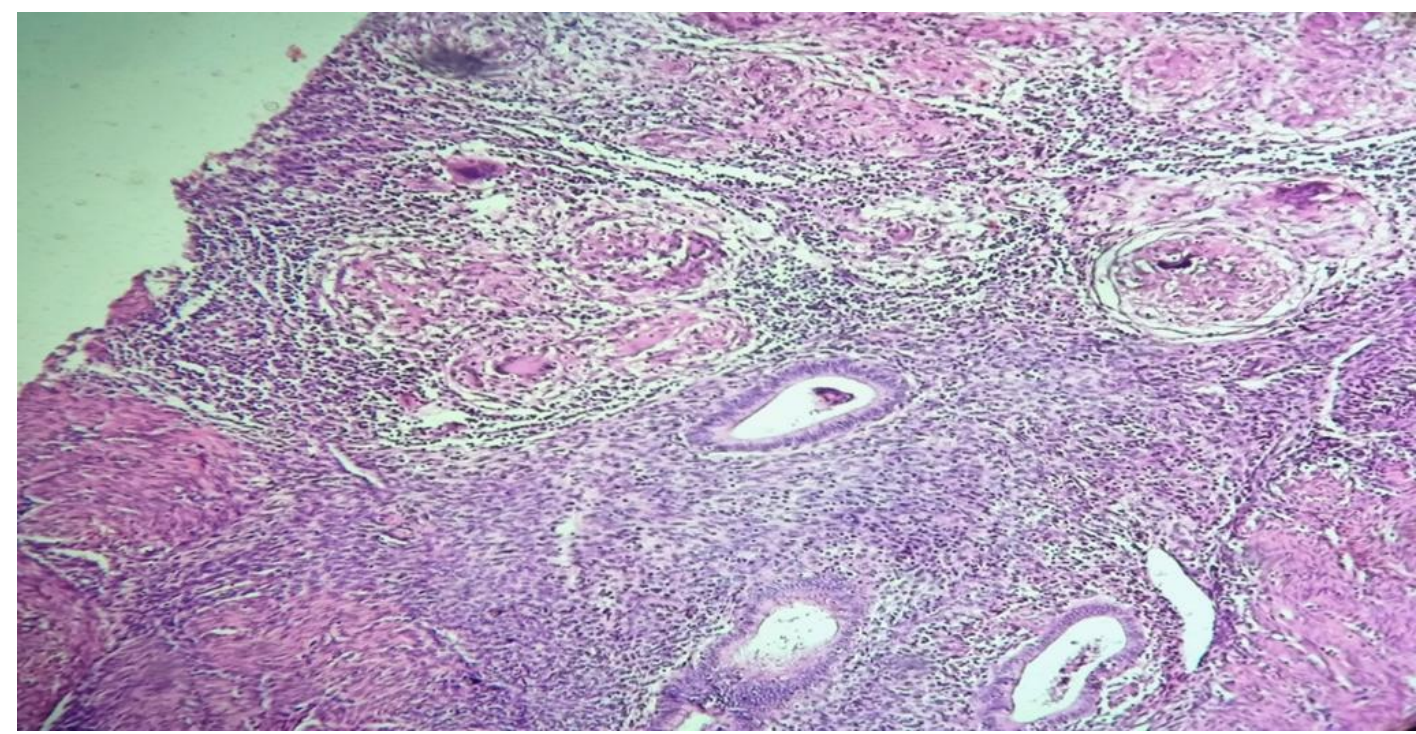

Photo no -2. TB Endometritis showing endometrial glands (thick black arrow) along with granulomas and typical langhans giant cells (thin black arrow) (H\&E,10X) 


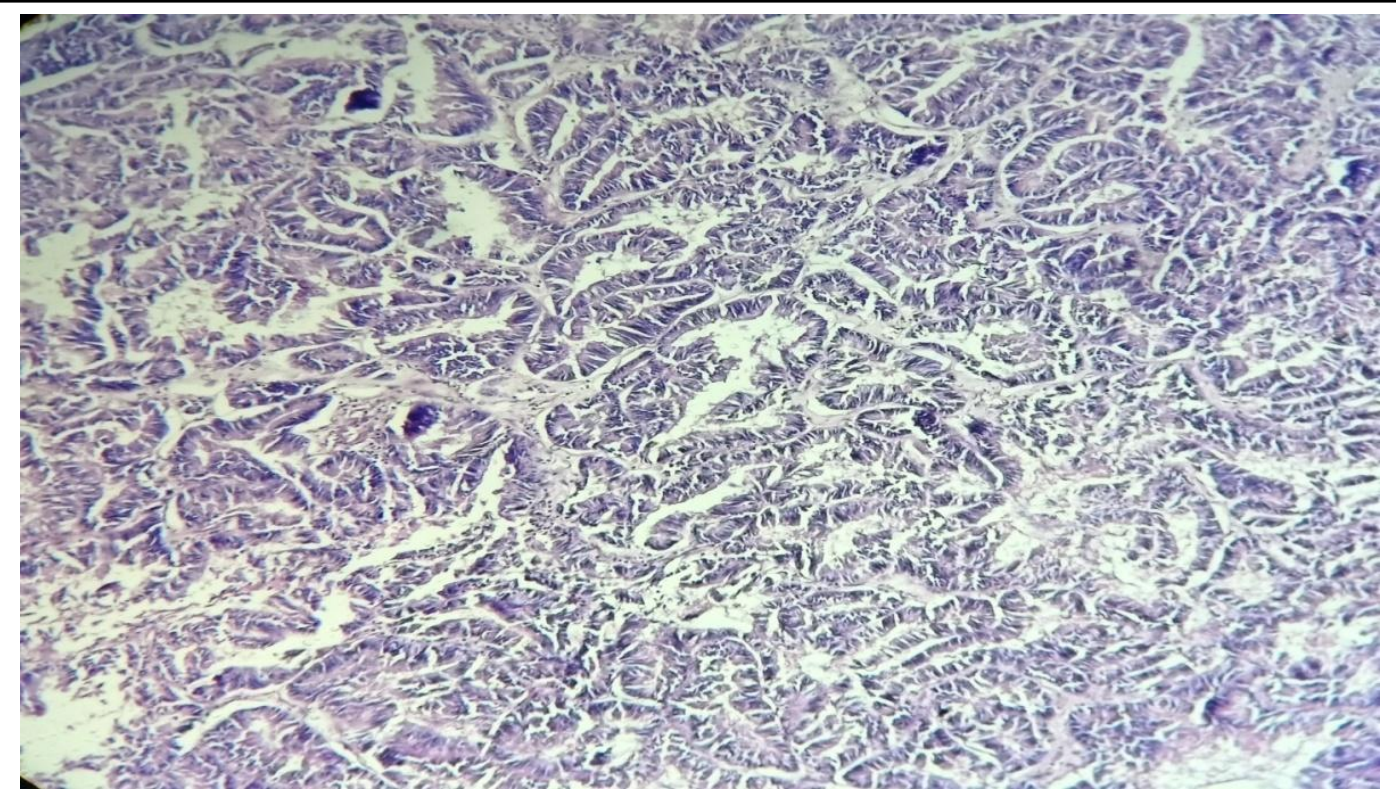

Photo no -3. Well differentiated Adenocarcinoma of Endometrium showing tumour tissue composed of numerous crowded glands with hyperchromatic pleomorphic nuclei (H\&E, 10X).

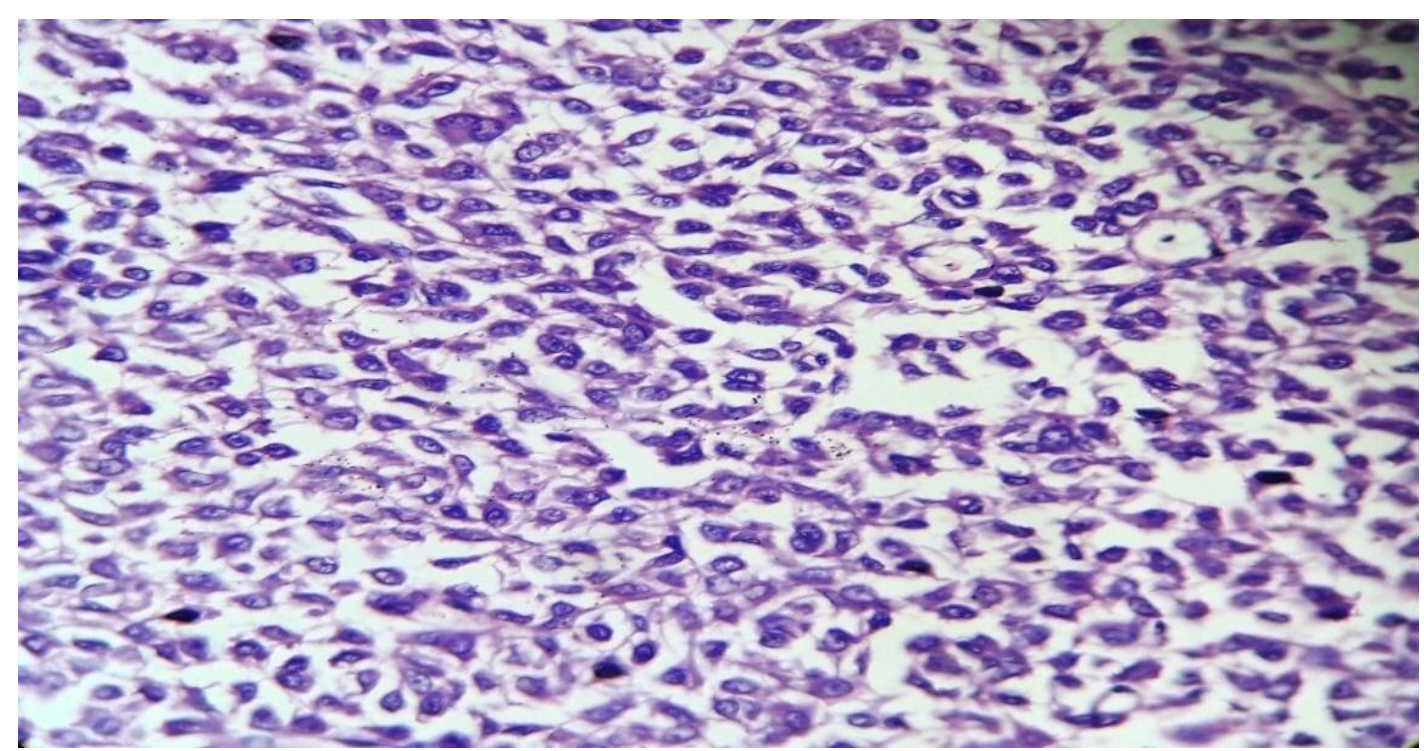

Photo no -4. Low grade Stromal sarcoma of Endometrium showing monomorphic large oblong to spindl shaped cells with vesicular nuclei and scant eosinophilic cytoplasm (H\&E, 40X)

\section{Discussion}

The present study was undertaken to study the spectrum of histopathological changes of endometrium in perimenopausal and postmenopausal women. Along with histology other observations were also made. In the present study the highest incidence of abnormal bleeding was noted in the age group of 41-50 years i.e. $64.7 \%$. Similar observation was made by other workers like Rajshri et al ${ }^{12}$ (2013), Kavita et al ${ }^{13}$ (2015), M. B. Swami et al. ${ }^{14}(2015), \quad$ B. S Nithyananda et $\mathrm{al}^{15}$ (2017), who reported the incidence as $73.94 \%, 74.8 \%, 64.0 \%$ and $70 \%$ respectively.

Majority of women 230 cases $(67.65 \%)$ were presented with menorrhagia, 70 cases $(20.58 \%)$ with Metrorrhagia, 18 cases (5.30\%) with Menometrorrhagia, 12 cases (3.53\%) with Polymenorrhea, 10 cases $(2.94 \%)$ with Postmenopausal bleeding. In the study Conducted by Rajshri et al (2013) the main presenting complaint was Menorrhagia (48.86\%), followed by metrorrhagia (31.55\%), and Post-menopausal bleeding $(26.05 \%)$. In the study Conducted by 
Kavita et al (2015) the main presenting complaint was Menorrhagia (62.1\%), followed by Polymenorrhea (11.6\%), Menometrorrhagia (9.5\%) and Post-menopausal bleeding (16.8\%).

In perimenopausal women, Proliferative endometrium was most common accounting for $58.64 \%$, which is comparable with study done by Rajshri et al (2013); 34.09\% and Kavita et al(2015); 34.7\%. Secretory endometrium was found in 47 cases in present study accounting for $21.36 \%$ which was comparable with study done by M. B. Swami et al (26.8\%).In the study done by Rajshri et al and Kavita et al there is lower incidence of Secretory endometrium that is in $7.95 \%$ and $7.4 \%$ respectively.

Atrophic endometrium was seen in $2.28 \%$, which was comparable with studies done by M. B. Swami et al $(2.6 \%)$ and Rajshri et al $(2.27 \%)$. Disordered Proliferative Endometrium was noted in $3.64 \%$, which was slightly higher in other studies. TB Endometritis was observed in $0.90 \%$, which was comparable with studies done by M. B. Swami et al (1.1\%) and Rajshri et al (1.13\%). Endometrial Polyp in present study was found to be $4.10 \%$, this was comparable with studies done by Rajshri et al $(3.40 \%)$, M. B. Swami et al (5.3\%), and Kavita et al $(6.3 \%)$. In our study, Simple Endometrial Hyperplasia constitutes 5.0\% of cases, whereas other studies had a higher incidence. Complex Hyperplasia Without Atypia was noted in $1.82 \%$, which was comparable with the study of M. B. Swami et al (1.1\%), and Kavita et al $(1.0 \%)$. In present study, Endometrial Carcinoma accounted for $0.45 \%$ of perimenopausal cases; this was comparable with the study of Kavita et al, also noticed $1.0 \%$ of cases.

\section{In Postmenopausal Women}

In the study done by Rajshri et al (2013) Proliferative endometrium were $19.35 \%$ and $\mathrm{M}$. B. Swami et al (2015) observed $18.3 \%$ of cases. In the present study, Proliferative endometrium in postmenopausal women were found to be $20.0 \%$, which was comparable with the study of and M. B. Swami et al. The study by Kavita et al (2015) had observed Rajshri et al a slight lower incidence $12.60 \%$ of cases.

Secretory endometrium was found in $12.5 \%$, which was comparable with study done by Rajshri et al (2013), who had observed $12.90 \%$. M. B. Swami et al (6.7\%) and Kavita et al (9.4\%) observed slightly lower incidence. Atrophic endometrium was seen in $47.5 \%$ in the present study, which was comparable with study done by M. B. Swami et al,who had observed $41.7 \%$.In present study, Disordered Proliferative Endometrium was noticed in $8.34 \%$ of cases, which was comparable with study done by Rajshri et al and Kavita et al ,who had observed $6.45 \%$ and $6.2 \%$ respectively.

Endometrial Polyp in present study was found to be $2.15 \%$, whereas studies done by M. B. Swami et al found $8.3 \%$, and Kavita et al noticed $6.2 \%$ respectively. In our study, Simple Endometrial Hyperplasia constitutes $5.0 \%$ of cases, which was comparable with M. B. Swami et al (3.4\%). Complex Hyperplasia without Atypia was noted in $0.83 \%$, whereas the other studies have found a higher incidence.

In present study, Endometrial Carcinoma accounted for $2.5 \%$ (3 cases)of postmenopausal cases; Rajshri et al found (3 cases) 9.67\%,M. B. Swami et al observed 3 cases( $5.0 \%$ ), and Kavita et al noticed 2 cases( $6.2 \%$ ) respectively. Stromal tumour were observed in $0.83 \%$ which was comparable with M. B. Swami et al (1.7\%).

\section{Conclusion}

Abnormal uterine bleeding affects women of perimenopausal and postmenopausal age group which is alarming and needs thorough evaluation including histological patterns and etiopathological factors. In a tertiary care center, it is hereby the duty of treating doctor to screen these patients. Histopathological study of the endometrium is the most common investigation employed by Gynaecologists throughout the world to evaluate abnormal uterine bleeding, and is particularly important in postmenopausal women 
to rule out malignancy and thereby plan for treatment modalities.

Sampling of endometrium should be considered in all women over the age of 40 years with abnormal bleeding in order to diagnose benign and malignant conditions and also to decide the mode of treatment to be given. This study is therefore conducted in order to determine the various histological variations in the endometrium among peri and postmenopausal women in a tertiary care center. Abnormal uterine bleeding is a major health problem that adversely affects the lives of women, therefore the sole target is to improve the patients symptoms and quality of life by proper diagnosis and treatment.

\section{References}

1. Schroeder R.Endometrial Hyperplasia in relation to Genital Function. American Journal of Obstetrics and Gynaecology. 1954;68(1): 294-309.

2. Tavassoli FA, Devilee P.Pathology and genetics of tumours of the breast and female genital organs. 2003: 221-232.

3. Bhosle A, Fonseca M. Evaluation and histopathological correlation of abnormal uterine bleeding in perimenopausal women. Bombay Hospital J. 2010; 52(1):69-72.

4. Fritz MA, Speroff L. Clinical gynaecologic endocrinology, and infertility. 8th ed. Lippincott Williams \& Wilkins; 2011.

5. Cornitescu Fl, Tanase F, Simionescu C, Iliescu D. Clinical, histopathological, and therapeutic considerations in nonneoplastic abnormal uterine bleeding in menopause transition. Rom J Morphol Embryol. 2011; 52(3):759-65.

6. Berek \& Novak's Gynaecology. $14^{\text {th }}$ Edition; p.1324-1325.

7. Goodman A. Abnormal genital tract bleeding. Clinical Cornerstone. 2000; 3(1):25-35.
8. Oriel KA, Schrager S. Abnormal uterine bleeding. Am Fam Physician. 1999; 60(5):1371-82

9. Creasman WT. Endometrial cancer: incidence, prognostic factors, diagnosis, and treatment. Semin Oncol. 1997;24:S1140.

10. Smith-Bindman R, Kerlikowske K, Feldstein VA, Subak L, Scheidler J, Segal $\mathrm{M}$ et al. Endovaginal ultrasound to exclude endometrial cancer and other endometrial abnormalities. JAMA. 1998; 280:1510-17.

11. Choudhary S, Berkley C, Warren M. Perimenopausal vaginal bleeding: Diagnostic evaluation and therapeutic options. Journal of women's health 2011; 21(3): 302-10.

12. Damle RP, Dravid NV, Suryawanshi KH, Gadre AS, Bagale PS, Ahire N. Clinicopathological spectrum of endometrial changes in peri-menopausal and postmenopausal abnormal uterine bleeding: A 2 years study.JCDR. 2013 Dec; 7(12): 2774-2776.

13. Kavita Babbar K, Jogi S, Arya RC. Clinical pattern and spectrum of endometrial pathologies in perimenopausal and post-menopausal women: Experience in a tertiary care institute. JSAFOMS. 2015;3(1):9-1.

14. Swami MB, Sharma P. Histopathological evaluation of endometrium in pre and postmenopausal uterine bleeding. Indian Journal of Obstetrics and Gynaecology Research. 2015;2(4):264-9 .

15. Nithyananda BS, Bheeshma B, Anjum F. Histopathological Spectrum Of Endometrial Lesions Inperimenopausal and Postmenopausal Women In Abnormal uterine Bleeding. International Journal of Scientific Research .2017Sep 28;6(7). 